\title{
Identification of a State-Space Model by Subspace Technique to Air Pressure Control in Combustion Chambers
}

\author{
Ademar Gonçalves da Costa Junior*!, Flávio da Silva Vitorino Gomes ${ }^{\S *}$, Julio Elias Normey-Rico! \\ *Instituto Federal de Educação, Ciência e Tecnologia da Paraíba (IFPB), Laboratório de Instrumentação, Sistemas de \\ Controle e Automação (LINSCA), João Pessoa, PB, Brazil (e-mail: ademar.costa@ifpb.edu.br) \\ ${ }^{\S}$ Universidade Federal da Paraíba (UFPB), Centro de Energias Alternativas e Renováveis (CEAR), João Pessoa, PB, Brazil \\ (e-mail: flavio@cear.ufpb.br) \\ 'Universidade Federal de Santa Catarina (UFSC), Grupo de Pesquisa em Energias Renováveis (GPER), Florianópolis, SC, \\ Brazil (e-mail: julio.normey@ufsc.br)
}

\begin{abstract}
In industrial combustion chambers, there are several strategies to control the air-gas (fuel) ratio aiming at better thermal use of the reaction. In all of them, the pressure of the mixed gases must be controlled to do not affect the desired air-gas ratio of the mixture. To model the dynamical behavior of the air pressure control system for use in a combustion chamber, a time-invariant linear state-space model was identified. System identification can be used as an alternative to phenomenological models to describe the dynamical behavior of the system, as well as to the use of CFD (Computational Fluid Dynamics) found in the literature for combustion chambers. In this paper, a robust subspace identification technique is used to obtain a mathematical model based on state-space and the results obtained presented and discussed.

Resumo: Em câmaras industriais de combustão, existem diversas estratégias para o controle da relação ar-gás visando melhor aproveitamento térmico da reação. Em todas elas, a pressão dos gases misturados deve estar controlada para não afetar a taxa ar-gás desejada para a mistura. Para modelar 0 comportamento dinâmico do sistema de controle de pressão de ar para uso em câmara de combustão, um modelo de espaço de estado linear invariante no tempo foi identificado. A identificação do sistema pode ser utilizada como uma alternativa ao uso das equações fenomenológicas que governam 0 comportamento dinâmico do sistema, bem como ao uso de CFD (Computational Fluid Dynamics) encontrado na literatura para câmaras de combustão. Neste artigo, uma técnica robusta de identificação de subespaço é usada para obter um modelo matemático baseado no espaço de estados e os resultados obtidos são apresentados e discutidos.
\end{abstract}

Keywords: Air pressure control, combustion chamber, mathematical modeling, system identification, subspace identification, state-space model.

Palavras-chaves: Controle de pressão de ar, câmara de combustão, modelamento matemático, identificação de sistemas, identificação por subespaços, modelo de espaço de estados.

\section{INTRODUCTION}

The combustion process in chambers is present in many types of product processing industries and in the direct generation of thermal, electrical or mechanical energy (Soares, 2015).

Mullinger and Jenkins (2014) list among the principles of a combustion chambers: i) obtain a satisfactory product; ii) use minimum fuel and energy to achieve that product; iii) operate with the lowest possible manning levels; and, iv) achieve a satisfactorily long life with low maintenance costs. Furnace combustion chambers process, from now on called combustion chambers, involves achieving the best combination of these four objectives over the entire life, in other words, to produce a high-quality product at the lowest achievable cost.

To monitor and diagnose the combustion chambers, the use of CFD (Computational Fluid Dynamics) is applied to the study and analysis of different types and levels of fuel insertion and camera geometry (Auchet et al, 2008; Su and Zhao, 2010; Amblard et al, 2017; Ariwibowo, Safitra, and Santoso, 2017; Tran et al, 2017) However, CFD is very common to simulate the various phenomena involved in the unit operation, employing a large amount of data, not being convenient for online procedures (Marjanovic et al, 2016).

The use of alternative techniques to the process phenomenological equations, through system identification methods, has received recent contributions in several applications (Shujiao and Feng, 2012; Yi, 2016; Costa et al, 2016; Dantas et al, 2016; Hajizadeh et al, 2017). System identification has as one of the objectives, to obtain mathematical models through input and output data. These mathematical models can be used in the monitoring and/or control of variables of dynamical systems. The two main areas of system identification are prediction error methods (PEM) and subspace identification. 
Compared with PEM, subspace identification methods avoid two problems: (i) selecting the structure of the model to be used, (ii) explicitly parameterizing the model. These two advantages are more important for multivariable systems. Unlike the various PEM techniques, subspace identification techniques are non-iterative and are not based on non-linear optimization procedures, avoiding several computational problems, such as local minimum, convergence and initial conditions (Verhaegen and Dewilde, 1992; Van Overschee and De Moor, 1996; Katayama, 2005; Qin, 2006).

The objective of this paper is to present the results obtained for the mathematical modeling of the air pressure control stage of a combustion chamber of a ironmaking industry. A discrete state-space linear invariant-time (LIT) was obtained through subspace identification techniques, using a robust subspace identification algorithm for the combined deterministic-stochastic case proposed by Van Overschee and De Moor (1996).

The rest of this paper is organized as follows: in section 2 the combustion chamber process is briefly described; in section 3 are presented the main theoretical basis of robust subspace identification algorithm for the combined deterministicstochastic case; section 4 presents the results obtained and finally, section 5, points out the final considerations of the paper.

\section{COMBUSTION CHAMBER}

Lackner et al (2013) state that the combustion is a series of exothermic chemical reactions between substances, including a combustible reactant, known as fuel, and an oxidizer, usually air or oxygen. The efficiency of the combustion process and the temperature to be maintained are affected by a number of parameters, including those of the environment, construction and operation.

In general, the mathematical models involved in this whole combustion chamber process are based on the chemical reactions provided in the gas mixture, on the geometry of the equipment used and on the aerodynamics of the injected air. This complex mathematical model is not presented in this article, and can be found in Lackner et al (2013), Mullinger and Jenkins (2014), Trivellato and Labiscsak (2015) and Strommer et al (2017).

One common type of control for combustion chambers is called Air-Fuel Ratio (AFR) control. A main goal of heating furnace control is guaranteeing the combustion process on the condition of perfect air-fuel-ratio. When AFR is excessively high, heat of chamber can take away by remnant air, heat energy loss increases; when AFR is excessively low, combustion is not sufficient, then wasting fuel and polluting environment. Thus air-fuel-ratio is a important link in the heating furnace control process (Cao et al, 2006).

A typical air-fuel ratio diagram for combustion chambers is shown in Fig. 1. There are two PID controllers to guarantee the correct flow of air and fuel, respectively, and a ratio controller as master of them to maintain the flows above the correct ratio. This ratio is dependent on the type of fuel and the amount of oxygen in the air and is directly related with the maximum efficiency (heat transfer) in the combustion chamber.

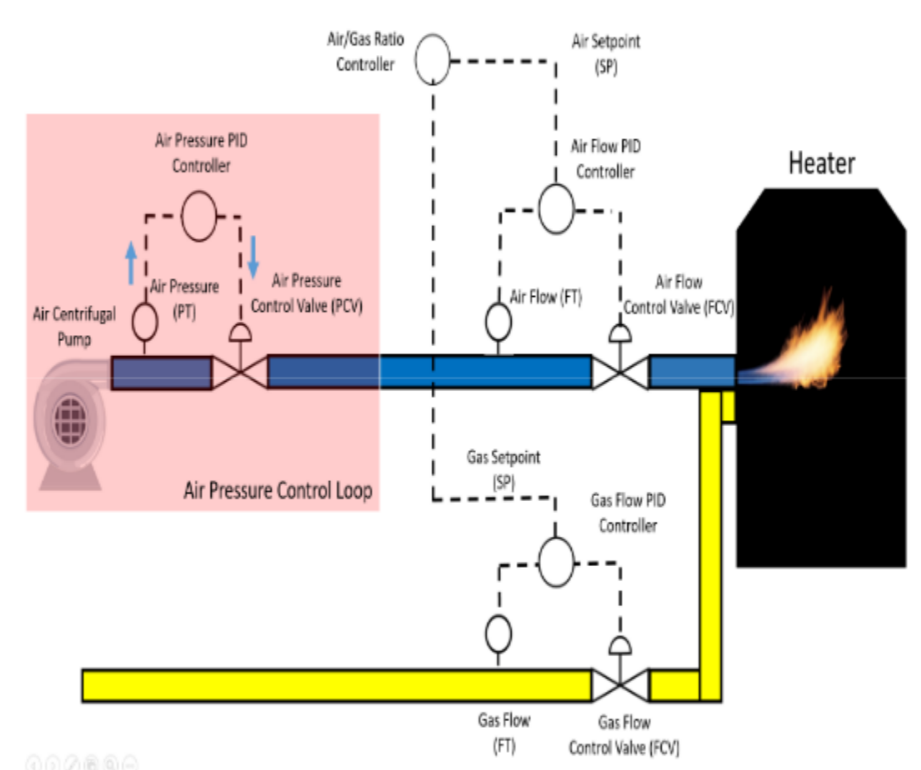

Fig. 1 - Typical air-fuel ratio diagram for combustion chambers.

This kind of combustion chamber is responsible to heat a waste gas $(\mathrm{CO} 2+\mathrm{N} 2+$ other minor components) that will remove the moisture of pulverized coal inside the coal grinder machine. This fuel is injected in the blast furnace through the tuyeres in the ironmaking process.

The objective of this study is the air pressure control loop that appears highlighted on the left side of Fig. 1. The air pressure PID control loop is responsible for maintaining the correct pressure in the airline to guarantee the final AFR, mitigating the variations that came from the air centrifugal pump.

The air pressure transmitter (PT) consists of a diaphragm installed in the airline, 2 meters before the air pressure control valve (PCV). This sensor is adjusted to work with a range of $0-2000 \mathrm{mmH2O}$. The PCV is composed by a butterfly valve coupled with an electrical motor as an actuator ( $0-100 \%$ of opening). It is important to note that the pressure control circuit was installed at some distance from the flow control circuit to prevent mechanical coupling, which would cause disturbances between them.

\section{ROBUST SUBSPACE IDENTIFICATION ALGORITHM}

In subspace identification, derived from the input and output data set of a dynamic system, the input $\left(U_{p}\right.$ and $\left.U_{f}\right)$ and output $\left(Y_{p}\right.$ and $\left.Y_{f}\right)$ Hankel matrices are formed. Hankel's matrices of past " $p$ " and future " $f$ " input are defined, respectively (Van Overschee and De Moor, 1996):

$$
U_{p} \triangleq U_{0 \mid i-1} \triangleq\left(\begin{array}{cccc}
u_{0} & u_{1} & \ldots & u_{j-1} \\
u_{1} & u_{2} & \ldots & u_{j} \\
\vdots & \vdots & \ddots & \vdots \\
u_{i-1} & u_{N} & \ldots & u_{i+j-2}
\end{array}\right)
$$




$$
U_{f} \triangleq U_{i \mid 2 i-1} \triangleq\left(\begin{array}{cccc}
u_{i} & u_{i+1} & \ldots & u_{i+j-1} \\
u_{i+1} & u_{i+2} & \ldots & u_{i+j} \\
\vdots & \vdots & \ddots & \vdots \\
u_{2 i-1} & u_{2 i} & \ldots & u_{2 i+j-2}
\end{array}\right)
$$

where $U_{p}, U_{f} \in \mathbb{R}^{m i \times j}$ with the subscript $k_{1} \mid k_{2}$ indicating the first column of the subspace matrix/vector begins at the discrete time $k_{1}$ and ends at $k_{2}$. The index $j$ (number of columns) is typically equal to $s-2 i+1$, implying that all given data samples are used. The output block Hankel matrices, $Y_{p}, Y_{f} \in \mathbb{R}^{l i \times j}$ are defined in a similar way to the matrices (1a) and (1b). The matrices $Y_{f}^{-}, U_{f}^{-}$on the other hand, are defined by shifting the border between past and future one block row down.

There are several forms of state-space representation. The basic idea of subspace identification methods is to estimate the dynamical system order $n$, and the matrices $A, B, C, D$, and $K$ of the linear invariant-time (LIT) discrete state-space model (2a)-(2b), from the availability of the dynamical system acquired data set. The innovation form is the one most commonly used in system identification, given by Qin (2006):

$$
\begin{aligned}
x_{k+1} & =A x_{k}+B u_{k}+K e_{k} \\
y_{k} & =C x_{k}+D u_{k}+e_{k}
\end{aligned}
$$

where $x_{k} \in \mathbb{R}^{n}$ (internal state vector), $y_{k} \in \mathbb{R}^{l}$ (output vector), $u_{k} \in \mathbb{R}^{m}$ (input vector), and $e_{k} \in \mathbb{R}^{m}$ is white noise. In these vectors, $n$ is the dimension of the state vector and represents the system order too, $m$ is the input dimension, and $l$ is the output dimension. $A \in \mathbb{R}^{n \times n}$ is the system matrix, $B \in \mathbb{R}^{n \times m}$ is the input matrix, $C \in \mathbb{R}^{l \times n}$ is the output matrix, $D \in \mathbb{R}^{l \times m}$ is the direct feedthrough matrix, and $K \in \mathbb{R}^{l \times m}$ is the Kalman gain.

A scheme of the robust combined deterministic-stochastic identification algorithm used in this paper is illustrated in Fig. 2.

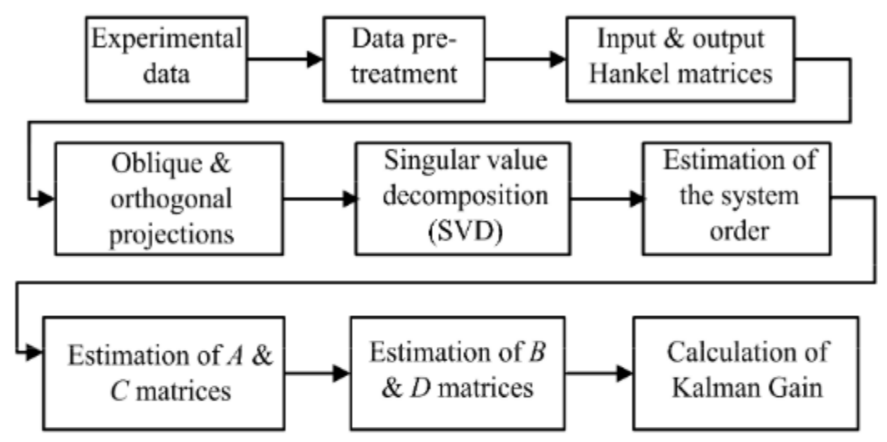

Fig. 2 - Scheme of the robust combined deterministicstochastic identification algorithm.

The robust subspace identification algorithm for the deterministic-stochastic case is started by calculating the oblique $\left(\mathcal{O}_{i}\right)$ and orthogonal $\left(Z_{i}\right)$ projections, respectively by:

$$
\begin{gathered}
\mathcal{O}_{i}=Y_{f} / U_{f} W_{p}, \quad z_{i}=Y_{f} /\left[\begin{array}{l}
W_{p} \\
U_{f}
\end{array}\right], \\
Z_{i+1}=Y_{f}^{-} /\left[\begin{array}{c}
W_{p}^{+} \\
U_{f}^{-}
\end{array}\right]
\end{gathered}
$$

with

$$
W_{p}=\left(\begin{array}{c}
Y_{p} \\
U_{p}
\end{array}\right)
$$

where $W_{p} \in \mathbb{R}^{(m i \times l i) \times j}$ is the matrix of past input and output data.

In (3), the projection $z_{i}$ could be considered an optimal prediction of the future output $Y_{f}$, given the past input and output data $W_{p}$ and the future input data $U_{f}$. The interpretation for $Z_{i+1}$ is that the offset projection of the edge between past and future one down (Van Overschee and De Moor, 1996). It can be noticed the oblique and orthogonal projections do not depend on the calculations of the statespace matrices but only the input and output data.

The system order is determined by inspecting the singular values in $S$ and partition the SVD accordingly to obtain $U_{1}$ and $S_{1}$. The matrices $\Gamma_{i}$ and $\Gamma_{i-1}$ are determined as:

$$
\Gamma_{i}=U_{1} S_{1}^{1 / 2}, \Gamma_{i-1}=\underline{\Gamma_{i}}
$$

where $\Gamma_{i}$ denotes $\Gamma_{i}$ without the last $l$ rows.

To calculate the matrices $A$ (with stability guarantee) and $C$ can be extracted from $\Gamma_{i}$.

$$
A=\Gamma_{i}^{\dagger} \cdot\left[\begin{array}{c}
\bar{\Gamma}_{l} \\
0
\end{array}\right]
$$

where 0 represent $l$ rows of zeros, and $\bar{\Gamma}_{l}$ denotes $\Gamma_{i}$ without the first $l$ rows. The matrix $C$ can be determined from the first $l$ rows of $\Gamma_{i} \cdot \Gamma_{i}^{\dagger}$ denotes the Moore-Penrose inverse of $\Gamma_{i}$.

$B$ and $D$ matrices are computed as:

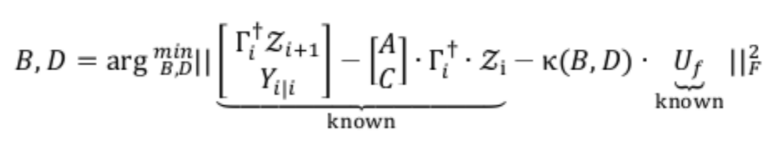

with $\|\cdot\|_{F}^{2}$ refers to the Frobenius norm squared, and $\kappa(B, D)$ refers to the linear matrix function defined by

$$
\kappa \triangleq\left[\begin{array}{c}
\left(B \mid \Gamma_{i-1}^{\dagger} \cdot H_{i-1}^{d}\right)-A \cdot \Gamma_{i}^{\dagger} \cdot H_{i}^{d} \\
(D \mid 0)-C \cdot \Gamma_{i}^{\dagger} \cdot H_{i}^{d}
\end{array}\right]
$$

The problem can be solved by either using a optimization algorithm, or by rewriting the function between the norm 
signs in (7) as an explicit linear combination of $B$ and $D$ and solving this set of equation in a least squares sense, this second way is used in this paper (Van Overschee and De Moor, 1996).

Kalman gain in the forward innovation model by solving the Riccati equation in (9):

$$
K=\left(G-A P C^{T}\right)\left(\Lambda_{0}-C P C^{T}\right)^{-1}
$$

where

$$
\begin{gathered}
P=\left(A P A^{T}\right)+\left(G-A P C^{T}\right)\left(\Lambda_{0}-C P C^{T}\right)^{-1}\left(G-A P C^{T}\right)^{T} \\
E\left[x_{k}^{S}\left(x_{k}^{S}\right)^{T}\right]=\Sigma^{S}=A \Sigma^{S} A^{T}+Q \\
E\left[y_{k} y_{k}^{T}\right]=\Lambda_{0}=C \Sigma^{S} C^{T}+R \\
E\left[x_{k+1}^{S} y_{k}^{T}\right]=G=A \Sigma^{S} C^{T}+S
\end{gathered}
$$

with $P$ as the forward state covariance matrix, $\Sigma^{s}$ is the state covariance matrix, and $\Lambda_{0}, G$ are the output covariance matrices also considered as Markov parameters of the deterministic linear time invariant system, as described in (Van Overschee and De Moor, 1996).

A detail of the procedure can be found in Costa Junior et al (2019), derived from the procedure described in Van Overschee and De Moor (1996), for the deterministicstochastic case of the subspace identification technique used.

\section{RESULTS}

The dataset used in this paper was obtained from a combustion chamber (hot gas generator) inserted in a hotblast stove. This equipment is responsible for heat the air that will be injected in the furnace combustion chamber during the production of iron in a ironmaking company. The process variable (PV) is the air pressure in line $(\mathrm{mmH} 2 \mathrm{O})$ and the manipulated variable (MV) is the percentage of valve opening after the centrifugal pump. The sampling time used if of 1 second. In the data pre-treatment stage, in addition to the data being normalized to 1 , outliers and offset values of the data are also removed, and no filter type is applied. The data set is shown in Fig. 3.
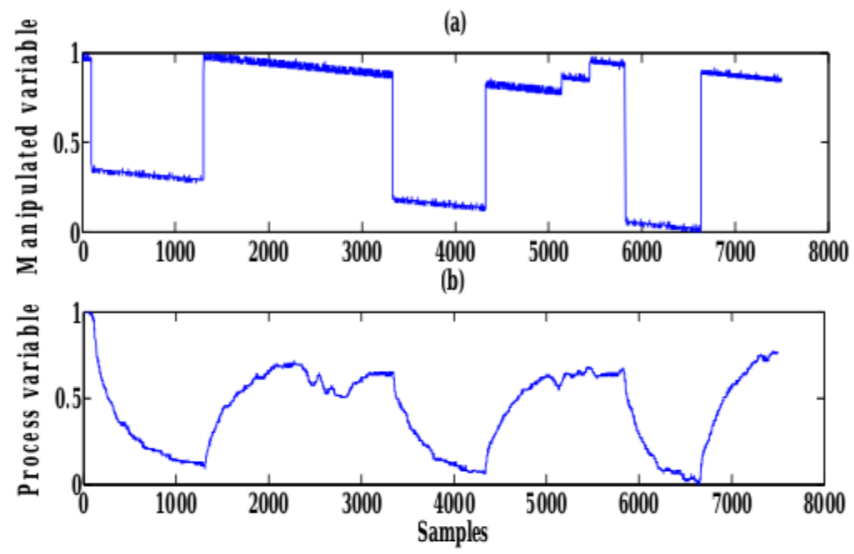

Fig. 3 - Combustion chamber normalized data set, after the data pre-processing step. (a) Manipulated variable (MV), and (b) process variable (PV).
The order of the model $(n)$ is chosen based on the inspection of the gap of the singular values calculated using (9). According to the results shown in Fig. 4, the investigation indicates that the order of the model is equal to 1 .

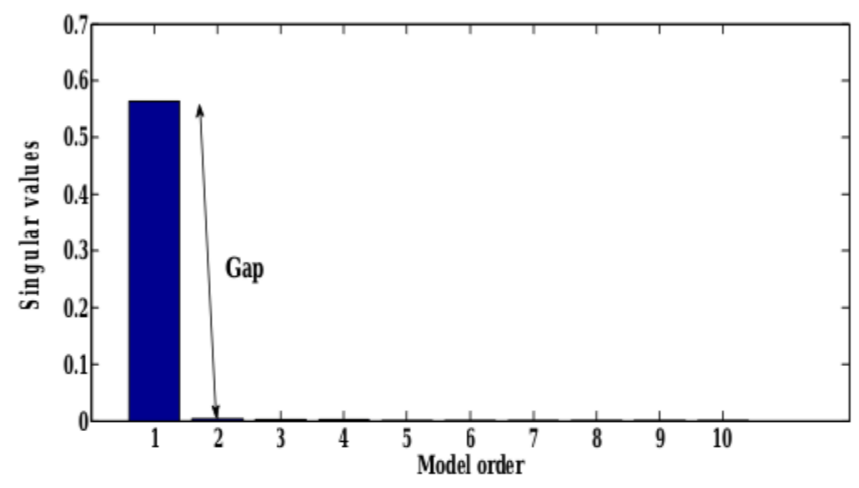

Fig. 4 - SVD using the robust combined deterministicstochastic subspace identification algorithm.

For the estimation and validation steps in the systems identification procedure, the MRSE (Mean Relative Square Error) index is used to measure the goodness of the fit between simulated response and measurement data. MRSE index is calculated as:

$$
M R S E=\left[1-\left(\frac{1}{l} \sum_{i=1}^{l} \sqrt{\frac{\sum_{k=1}^{N}\left(\left(y_{k}\right)_{i}-\left(\hat{y}_{k}\right)_{i}\right)^{2}}{\sum_{k=1}^{N}\left(\left(y_{k}\right)_{i}\right)^{2}}}\right)\right] \times 100 \%
$$

where $l$ is the number of outputs of the dynamical system, $y_{k}$ is the experimental output data used for the validation, and $\hat{y}_{k}$ is the estimated output data.

From the 7500 set of input and output data samples, half were used for estimation and the other for validation. The MRSE index values the robust combined deterministic-stochastic identification algorithm and MOESP (Multivariable Output Error State sPace), which is a subspace identification technique for the deterministic case and used for comparative purposes in this paper, are illustrated in Table 1. In addition, the processing times of the two algorithms were calculated and are also shown in Table 1.

Table 1. MRSE index and computational time for subspace identification algorithms.

\begin{tabular}{|c|c|c|}
\hline Method & $\begin{array}{c}\text { MRSE index } \\
\text { (\%) }\end{array}$ & $\begin{array}{c}\text { Comput. } \\
\text { time (s) }\end{array}$ \\
\hline $\begin{array}{c}\text { MOESP - deterministic } \\
\text { case }\end{array}$ & 89,69 & 5.46 \\
\hline $\begin{array}{c}\text { Robust combined } \\
\text { deterministic-stochastic }\end{array}$ & 97.13 & 0.021 \\
\hline
\end{tabular}

Fig. 5 illustrates the estimated output of the combustion chamber process variable (air pressure) using the subspace identification algorithms, MOESP (deterministic case) and the robust algorithm (deterministic-stochastic case). With the 
data in Table 1, it is observed that the robust algorithm presents a superior result in relation to MOESP, regarding the MRSE index $(7.5 \%$ higher) and the computational time, using one-step-ahead prediction.

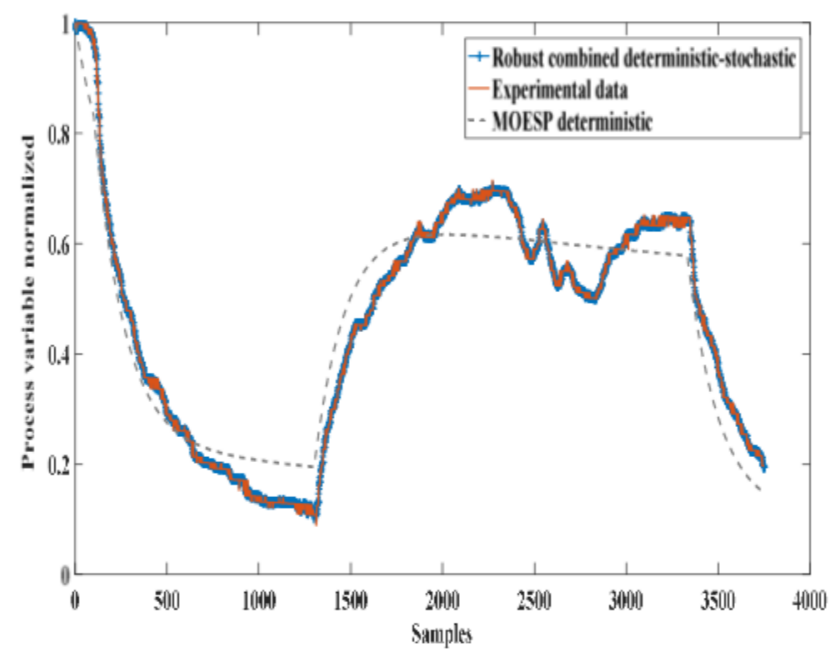

Fig. 5 - Estimated and real outputs for combustion chamber based on the subspace identification algorithms.

In Fig. 6, it can be observed that in the validation step, the robust algorithm used in this paper presents better results than MOESP. The inclusion of the noise model (stochastic case) through the estimated Kalman gain contributes to its better results than the MOESP, with RMSE indices of $96.57 \%$ and $84.37 \%$, respectively.

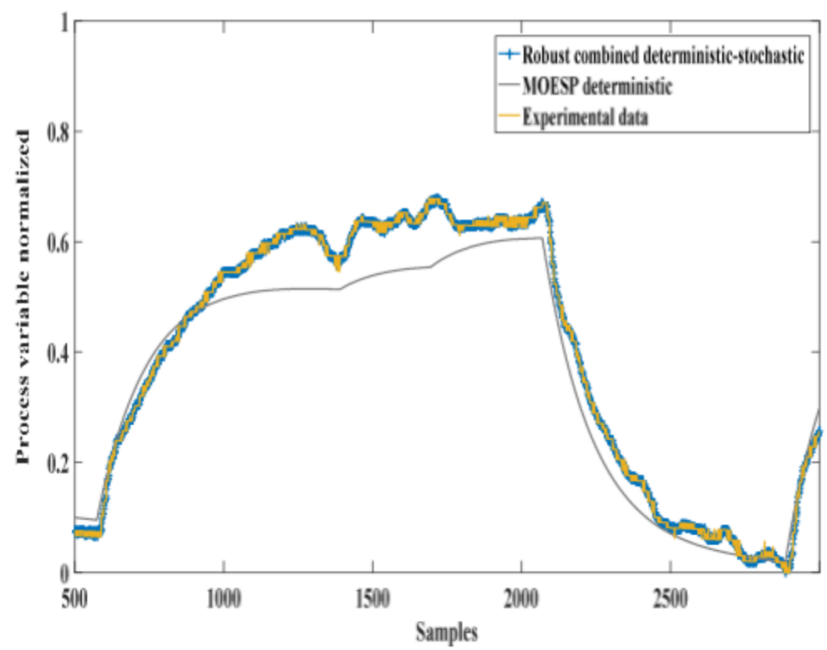

Fig. 6 - Validation data for combustion chamber based on the subspace identification algorithms.

These results suggest that the estimated LIT discrete state space model reached satisfactory results, showing the good properties of robust subspace identification algorithm for the combined deterministic-stochastic case proposed by Van Overschee and De Moor (1996).

\section{CONCLUSION}

In this paper, we present the results of subspace identification technique usage that allowed obtaining a good Linear Invariant-Time (LIT) state-space model in an air pressure control loop of a combustion chamber. These results suggest that the estimated LIT discrete state-space model reached satisfactory results, showing the good properties of robust subspace identification algorithm for the combined deterministic-stochastic case.

In future work for the dynamical system investigation, the state-space mathematical model will be used in the design of model-based advanced controllers, as a way of optimizing the air-fuel ratio in the combustion chamber.

\section{ACKNOWLEDGMENT}

The authors thank CAPES (Coordination for the Improvement of Higher Education Personnel), during the postdoctoral stage (A. G. C. J.) at the Federal University of Santa Catarina (UFSC), Federal University of Paraiba (UFPB), CNPq (National Council for Scientific and Technological Development) for project 305785/2015 - 0, and Federal Institute of Paraiba (IFPB).

\section{REFERENCES}

Amblard, B. et al (2017). CFD modeling of the coke combustion in an industrial FCC regenerator. Chemical Engineering Science. Vol. 170, pp. 731-742.

Ariwibowo, T. H., Safitra, A. G., and Santoso, H. (2017). Investigation on combustion characteristics of nonpremixed combustion in an 85 MWe wall firing boiler under various air-fuel ration using CFD. 2017 International Electronics Symposium on Engineering Technology and Applications (IES-ETA), Surabaya (Indonesia), pp. 20-26.

Auchet, O. et al. (2008). First-principles simplified modelling of glass furnaces combustion chambers. Control Engineering Practice, vol. 16, n. 12, pp. 1443-1456.

Cao, H. et al. (2006). Air-fuel-ratio optimal control of a gas heating furnace based on fuzzy neural networks. In: Wang J. et al (eds). Advances in Neural Networks. Lecture Notes in Computer Science, vol 3973. Springer.

Costa, A. G. et al. (2017). N4SID method applied to obtain a discrete-time linear state space system as a mathematical model of a jaw crusher prototype. 2017 Chilean Conference on Electrical, Electronics Engineering, Information and Communication Technologies (CHILECON), Pucon (Chile).

Costa, A. G. et al. (2019). Use of Subspace Identification Techniques for Solar Fields Mathematical Modeling, Simpósio Brasileiro de Automação Inteligente (SBAI 2019), Ouro Preto (Brazil). 
Dantas, T. S. S. et al. (2016). Nonlinear system identification of a refrigeration system. International Journal of AirConditioning and Refrigeration, vol. 24, n. 4, pp. 1-11.

Hajizadeh, I. et al. (2017). Multivariable recursive subspace identification with application to artificial pancreas systems. IFAC-PapersOnLine, vol. 50, n. 1, pp. 886-891.

Katayama, T. (2005). Subspace methods for system identification: a realization approach, Springer.

Lackner, M. et al (2013). Combustion: from basics to applications, Wiley.

Mullinger, P., and Jenkins, B. (2014). Industrial and process furnaces: principles, design and operation. ButterworthHeinemann.

Marjanovic, A. et al. (2016). Control of thermal power plant combustion distribution using extremum seeking. IEEE Transictions on Control Systems Technology, vol. 25, n. 5, pp. 1670-1682.

Qin S. J. (2006). An overview of subspace identification. Computers and Chemical Engineering, vol. 30, n. 10-12, pp. 1502-1513.

$\mathrm{Su}$, Y., and Zhao, B. (2010). CFD simulation of high temperature air combustion of coal gas at different air straddle angle. 2010 4th International Conference on Bioinformatics and Biomedical Engineering, Chengdu (China).

Shujiao, B., and Feng. D. (2012). Modeling for liquid-level control system in beer fermentation process. 31st Chinese Control Conference, Hefei (China), pp. 17391744.

Soares, C. (2015). Gas turbines: a handbook of air, land and sea applications, 2nd Ed. Elsevier.

Strommer, S. et al (2017). Modeling and control of the oxygen concentration in a post combustion chamber of a gas-fired furnace. IFAC-Papers Online, vol. 50, n. 1, pp. 13766-13771.

Tran, A. et al. (2017). Steam methane reforming furnace temperature balancing via CFD model-based optimization. 2017 American Control Conference (ACC), Seattle (United States), pp. 4165-4170.

Trivellato, F. and Labiscsak, L. (2015). The post-combustion chamber of steelmaking plants: role of ambient air in reactant exhaust. Applied Mathematical Modelling, vol. 39 , n. 1, pp. 19-35.

Van Overschee, P. and De Moor, B. (1995). A unifying theorem for three subspace system identification algorithms. Automatica, vol. 31, n. 12, pp. 1853-1864.

Van Overschee, P. and De Moor, B. (1996). Subspace identification for linear system: theory, implementation, applications, Doordrecht (Netherlands): Kluwer.

Verhaegen, M. and Dewilde, P. (1992). Subspace model identification, part i: The output-error state-space model identification class of algorithms. International Journal of Control, Vol. 56, n. 5, pp. 1187-1210. 